\title{
O Ferroviário como patrimônio cultural intangível
}

\section{The railway worker as intangible cultural heritage}

Viviane Regina Caliskevstz

Universidade Estadual de Ponta Grossa

\begin{abstract}
Resumo: Este ensaio faz parte de estudos preliminares que tem o intuito de pesquisar o papel do trabalhador ferroviário paranaense enquanto parte integrante do acervo patrimonial ferroviário brasileiro, de forma a compreender o seu papel na representatividade simbólica que a ferrovia tem diante da sociedade. Essa participação sugere, portanto, o seu entendimento enquanto um "Patrimônio vivo da sociedade". Para alcançar esse objetivo é necessário compreender as diferentes abordagens sobre a constituição do conceito de patrimônio cultural.
\end{abstract}

Palavras-chave: Patrimônio cultural.Ferroviário.Memória.Patrimônio vivo.

Abstract: The present essay is part of the preliminary studies aimed at examining the role of the railway workers in the state of Paraná as part of the Brazilian railway heritage collection, understanding their role in the symbolic representation of the railroad in the eyes of the society. Such participation suggests, therefore, that they should be considered "society's living heritage". In order to do so, it is necessary to comprehend the different approaches regarding the development of the concept of cultural heritage.

Keywords: Cultural heritage. Railway worker. Memory. Living heritage. 


\section{INTRODUÇÃO}

As discussões sobre o patrimônio cultural não são recentes, apareceram no cenário social europeu já no século $\mathrm{XV}$, com denominações que variavam entre Antiguidades e Monumentos até constituir-se no atual conceito de patrimônio. Essas mudanças são caracterizadas por diferentes evoluções no contexto social europeu. Essas transformações sociais também influenciaram as manifestações culturais no Brasil, assim como os diversos critérios de classificação do patrimônio cultural nacional brasileiro.

O conceito de "Patrimônio" surgiu na Europa em meados do século XIX, mais precisamente na Grã-Bretanha, enquanto um "bem" (objeto) material condicionado ao usufruto de uma estrutura familiar ou de um grupo social elitizado, materializado num espaço e caracterizado por um passado comum. O termo patrimônio está ligado também a outros exemplos de bens materiais, de "natureza econômica, moral, religiosa, mágica, política, jurídica, estética, psicológica, fisiológica" (GONÇALVES, 2003, p.27), natural, histórico-artístico (representado em sua grande maioria por obras de artes e edificações), e recentemente, "intangível ou imaterial" (ligado aos saberes e às técnicas sociais).

Atualmente, o entendimento do conceito de patrimônio vai além dos exemplares artísticos e arquitetônicos com funções institucionais, que pertenceram ao passado, tendo agora objetivos voltados à proteção de bens tangíveis e intangíveis ligados aos valores artísticos, memoriais e científicos. A relação do patrimônio ligado a uma instituição pública aparece nos estudos de Françoise Choay (2001), tendo como foco as cidades europeias. Para essa autora, o entendimento do patrimônio histórico cultural deve iniciar alguns séculos antes de sua conceituação, ocorrido no século XX.
A presente discussão propõe algumas abordagens sobre o processo de institucionalização do patrimônio cultural, sua influência nos trabalhos de preservação do acervo artístico brasileiro com enfoque nas políticas públicas, numa forma específica de compreensão do patrimônio ferroviário. Nessa discussão, a questão central permeia o papel da classe de trabalhadores ferroviários como parte importante da empresa ferroviária brasileira do século XIX, discutindo a falta de reconhecimento desses agentes no acervo que compõe o patrimônio cultural ferroviário, administrado pelo Instituto do Patrimônio Histórico e Artístico Nacional (IPHAN), visto que "o patrimônio ferroviário é formado por acervo material e imaterial, que se completam" (MONASTIRSKY, 2006, p. 10).

Esse acervo de bens materiais é formado por edificações, compostas pelas estações e seus pátios de manobras, distribuídas por centenas de cidades paranaenses, antigas casas de trabalhadores e oficinas, pelos trens e trilhos. Esses equipamentos e utensílios são relíquias do passado, e ainda encontram-se presentes no cotidiano de muitas cidades, assim como o referencial cultural intangível, representado na forma de histórias de vida e de lutas, pertencentes aos trabalhadores ferroviários.

O referencial teórico embasado nas obras de Abreu (2003); Choay (2001); Gonçalves (2003); Lemos (1981); Hobsbawm (2004); Monastirsky (1997; 2006); Santos (2006); Moreira (2008); Petuba (2005); Zambello (2005) e Inácio (2003)busca uma construção conceitual que atenda a problemática do presente ensaio, esclarecendo não só a construção histórica da categoria "patrimônio cultural" e suas subdivisões, mas também a criação do acervo que compõe o patrimônio ferroviário brasileiro e a falta de reconhecimento do trabalhador ferroviário como parte desse acervo. 


\section{O CONCEITO DE PATRIMÔNIO CULTURAL E SUA TRAJETÓRIA NA TRANSFORMAÇÃO DA SOCIEDADE}

Para compreender o atual conceito de patrimônio histórico é necessário considerar dois momentos da história europeia. Na análise feita por Choay (2001) o primeiro refere-se a Roma do século XV, com o despertar de interesse em preservar objetos achados em atividades arqueológicas, como forma de estudá-los. As ruínas viraram um local propício ao desenvolvimento intelectual, despertando um clima de sensibilidade na população que passou a defender as "relíquias" das intempéries do tempo e dos saqueadores.

A admiração e o fascínio que despertavam as obras de arte e a arquitetura das cidades, promovidas pelo orgulho da própria história romana, acarretaram as primeiras movimentações para a preservação das chamadas Antiguidades. O interesse por antiguidades descoberto pela sociedade da Idade Média foi o primeiropasso para o processo contemporâneo da institucionalização do patrimônio cultural, assim como para o surgimento da chamada cultura erudita ${ }^{1}$.

O segundo momento da consolidação do patrimônio diz respeito ao século XIX, através da consagração do chamado $\mathrm{Mo}$ numento Histórico, também com base no orgulho nacional, mas com maior intensidade. $\mathrm{O}$ ingrediente essencial para sua consolidação advém de uma tomada de consciência histórica social, acerca de suas obras de arte e de seus monumentos, não mais achados em escavações antigas, mas presentes no cotidiano do espaço urbano europeu. Ao buscar a origem do termo

${ }^{1}$ Cultura erudita: cultura dominante que desenvolveu universo próprio de legitimidade, expressopela filosofia, pela ciência e pelo saber produzido e controlado em instituições como universidades. monumento, Choay (2001) traduz o que foi a atmosfera do movimento cultural em que viviam os europeus do século XIX:

O sentido original do termo é do latim monumentum, que por sua vez deriva de monere("advertir", "lembrar") aquilo que traz à lembrança alguma coisa. A natureza afetiva do seu propósito é essencial: não se trata de apresentar, de dar uma informação neutra, mas de tocar, pela emoção, uma memória viva (...) sua relação com o tempo vivido e com a memória ou, dito de outra forma, sua função antropológica, constitui a essência do monumento (CHOAY, 2001, p.17/18).

A memória viva, representada pelas edificações, tornou-se a essência da preservação dos monumentos, principalmente, na França. $\mathrm{O}$ ato de conviver cotidianamente com construções e obras artísticas, fez com que a sociedade francesa iniciasse um movimento de preservação de seu espaço urbano. Contudo, a nostalgia despertada pelos monumentos acarretou num problema para o Estado, que agora tinha que expandir seu progresso urbanístico para outras áreas, já que o espaço já constituído não poderia ser substituído por novas construções. Como soluções foram criadas as primeiras comissões e decretos jurídicos como forma de classificar e legalizar os monumentos em diferentes grupos. São criadas três novas categorias de monumentos históricos (além dos já preservados remanescentes da Antiguidade - edifícios religiosos da Idade Média e alguns castelos):

Todas as formas de arte de construir, eruditas e populares ${ }^{2}$, urbanas e rurais, todas as categorias de edifícios, públicos e privados, suntuários $^{3}$ e utilitários foram anexadas

${ }^{2}$ Cultura Popular: forma de manifestação artística associada ao povo, às classes excluídas e dominadas socialmente. Essa cultura não esta ligada ao conhecimento científico, mas sim, ao conhecimento de senso comum.

${ }^{3}$ Relativo ao luxo, suntuoso. 
sob novas denominações: arquitetura menor, termo proveniente da Itália para designar as construções privadas não monumentais, em geral, edificadas sem a cooperação de arquitetos; arquitetura vernacular, termo inglês para designar os edifícios marcadamente locais; arquitetura industrial, das usinas, das estações, dos altos fornos (CHOAY, 2001, p.12).

Contudo, o sentimento nacionalista europeu despertado pelos monumentos, surge segundo uma jogada política que visava unicamente à proteção das propriedades das famílias nobres, do que propriamente uma proteção ao patrimônio histórico urbano. "Foi apenas a partir do ideário desencadeado pela Revolução Francesa que o significado de patrimônio estendeu-se do privado, para o conjunto dos cidadãos" (ABREU, 2003, p.35). Segundo essa autora, o movimento promovido por intelectuais patriotas contra o vandalismo que vinha sendo promovido por grupos revolucionários que tentavam destruir todas as aquisições de épocas anteriores, que a concepção de "bem comum" desenvolveu-se, juntamente com a própria ideia de "nação". As ações patriotas de preservação patrimonial buscavam na ideologia de "patrimônio como herança do povo", através da ideia de nação e identidade nacional, uma forma de proteção dos bens e do poder pertencentes aos nobres.

A emergência da noção de patrimônio, como bem coletivo associado ao sentimento nacional, dá-se inicialmente num viés histórico e a partir de um sentimento de perda. Era preciso salvar os vestígios do passado, ameaçados de destruição. Em 1832, Victor Hugo escreveu um artigo sobre a necessidade de proteger o patrimônio histórico, que enunciava uma espécie de lei moral que começou a ser formulada sobre o patrimônio a ser salvaguardado para todos os membros da comunidade nacional. Associado à direção histórica naquele momento, o conceito de patrimônio tendeu a ser absorvido como uma herança artística e monumental, na qual a população poderia se reconhecer sob o novo formato do Estado-nação (ABREU, 2003, p.35).

Atrelado a esse ideal de proteção, cria-se a terminologia "Humanidade" associada ao conceito de patrimônio, como forma de representar um bem coletivo nacional, "teoricamente disponível para toda a humanidade" (ABREU, 2003, p.36), levando a união do povo através do sentimento de pertencimento nacional.

Os novos parâmetros em que se encontram os monumentos do século XIX, não se limitam mais a construções individuais e únicas, representada pelo período das Antiguidades. Nesse momento na ordem de preservação estende-se as malhas urbanas e aglomerados edificados, numa onda que buscou transformar as cidades em museus a céu aberto. $\mathrm{O}$ ato de preservar cidades inteiras perdurou até meados do século $X X$, quandoo termo "monumento" toma status legal adquirindo o atual termo de Patrimônio, mediados agora pela UNESCO ${ }^{4}$.

Como mediação pública, surge em Paris, no ano de 1946, a organização conhecida como UNESCO, que responde aos vários objetivos sociais, inclusive os relacionados ao patrimônio cultural. Para Abreu (2003, p.36), a criação da UNESCO, no final da Segunda Guerra Mundial quebrou "antagonismos entre nações". Com o surgimento da vertente "universalista da nação de patrimônio da humanidade", com raízes iluministas, buscavam a relação de várias culturas nacionais. Para o antropólogo Claude Lévi -Strauss, (citado por ABREU 2003, p.37) a noção de cultura apresentava-se nesse momento como um calmante para os conflitos mundiais.

\footnotetext{
${ }^{4}$ United NationsEducational, Scientificand Cultural Organization (Organização das Nações Unidas para a Educação, a Ciência e a Cultura), instituição especializada da ONU, constituída em 1946 para proteger as liberdades humanas e incentivar o desenvolvimento cultural.
} 
O relacionamento entre as culturas seria a forma mais positiva de atualizar o ideário da igualdade dos homens, em suas realizações particulares. Delineava-se a ideia de que havia um patrimônio cultural a ser preservado e que incluía não apenas a historia e a arte de cada país, mas o conjunto de realizações humanas em suas mais diversas expressões. A noção de cultura incluía hábitos, costumes, tradições, crenças; enfim, um acervo de realizações materiais, e imateriais, da vida em sociedade (ABREU, 2003, p.37).

Para Strauss duas concepções culturais surgem nesse momento. A primeira diz respeito à diversidade e pluralidade cultural que existem no interior de cada país. A segunda afirma que a cultura é formada por bens materiais e imateriais (intangíveis). É no final do século XX que novas concepções e estudos focados em grupos historicamente discriminados e categorias criadas surgem como meios de compreender a diversidade cultural mundial.

Consecutivamente, no ano de 1983, outras definições da Unesco surgem para atender às novas demandas patrimoniais não mais restritas àEuropa, mas visando o patrimônio mundial. Classificado em três diferentes grupos, são considerados "patrimônio cultural":

O relacionamento entre as culturas seria a forma mais positiva de atualizar o ideário de igualdade dos homens, em suas realizações particulares. Delineava-se a ideia de que havia um patrimônio cultural a ser preservado e que incluía não apenas a historia e a arte de cada país, mas o conjunto de realizações humanas em suas mais diversas expressões (ABREU, 2003, p.37).

Nesse momento, a noção de cultural se altera e passa a incluir "hábitos, tradições, crenças", formando um acervo de bens materiais e imateriais, pertencentes a diferentes culturas e subculturas existentes num mesmo território nacional. Dessa forma, no ano de 1983, uma nova definição da Unesco surge para atender àdemanda patrimonial, não mais restrita àEuropa, mas visando o Patrimônio Mundial. Classificado em três diferentes grupos, são considerados "Patrimônio Cultural":

Os monumentos (obras arquitetônicas, de esculturas ou de pintura monumentais, elementos ou estruturas de caráter arqueológico, inscrições, cavernas e grupos de elementos que tenham um valor universal excepcional do ponto de vista da história, da arte ou da ciência); osconjuntos (grupos de construções isoladas ou reunidas que, em razão de sua arquitetura, de sua unidade ou de sua integração na paisagem, têm um valor universal excepcional do ponto de vista da história, da arte ou da ciência); os sítios (obras do homem ou obras combinadas do homem e da natureza, assim como as zonas, inclusive sítios arqueológicos, que tem um valor universal excepcional do ponto de vista histórico, estético, etnológico ou antropológico) (CHOAY, 2001, p.207).

Diante da nova definição de patrimônio feita pela Unesco, surgem elementos que merecem uma análise crítica. Primeiro a noção de valorempregado ao ato de preservação do patrimônio, que desde sua fundação na França, atribui a esse os seguintes valores: cognitivo, ligados àmemória histórica de uma sociedade em questão, mobilizadas pela ideologia nacional; econômico, relacionado à exploração turística de sua imagem, importante impulsionador da criação dos museus e fortemente vinculado à imagem patrimonial da atualidade; e artístico voltado para a valorização dos artistas nacionais, destinada a usos educacionais, científicos e práticos. São esses valores, principalmente nacionais, que sustentam ate os dias de hoje, a base para escolha do patrimônio.

Entretanto, problemas de ordem ideológica ${ }^{5}$ surgem, quando os valores atribuídos

${ }^{5}$ Marilena Chaui traz em sua obra “O que é Ideologia" um es- 
às escolhas dos patrimônios ficam a cargo de comissões e grupos de indivíduos, que determinam o que deve e como devem ser preservados tais patrimônios. Nesse sentido, surge um segundo elemento de análise, referente à classificação de patrimônio tangível e intangível.

Lemos (1981, p.07) defende que as expressões "Patrimônio Histórico ou Artístico", "abrange somente um segmento de um acervo maior, que é o chamado patrimônio cultural de uma nação ou de um povo". O autor atribui ao francês Hugues de Varine-Boham a discussão sobre a problemática do patrimônio cultural e a divisão desses, em três grandes categorias de elementos. A primeira categoria abarca os elementos pertencentes à natureza e ao meio ambiente.

São os recursos naturais, que tornam o sitio habitável, nessa categoria estão os rios, a água desse rio, os peixes, a carne desses peixes, as suas cachoeiras e corredeiras transformáveis em força motriz movendo rodas de moendas, acionando monjolos e fazendo girar incrivelmente rápidas as turbinas das usinas de eletricidade (LEMOS, 1981, p.08).

O segundo grupo de elementos "referese ao conhecimento, às técnicas, ao saber e ao saber fazer", (p.09) constituindo os chamados elementos intangíveis do acervo maior do patrimônio cultural.

Compreende toda a capacidade de sobrevivência do homem no seu meio ambiente. Vai desde a perícia no rastejamento de uma caça esquiva na floresta escura até às mais altas elucubrações matemáticas apoiadas

tudo de como se formam as ideologias: "Além de procurar fixar seu modo de sociabilidade através de instituições determinadas, os homens produzem ideias ou representações pelas quais procuram explicar e compreender sua própria vida individual, social, suas relações com a natureza e com o sobrenatural. Essas ideias ou representações, no entanto, tenderão a esconder dos homens o modo real como suas relações sociais foram produzidas e a origem das formas sociais de exploração econômica e de dominação política. Esse ocultamento da realidade social chama-se ideologia" (1980, p. 21). nos computadores de última geração, que dirigem no espaço cósmico as naves interplanetárias que estão a ampliar o espaço vital do homem (LEMOS, 1981, p.09).

O terceiro grupo é tido como o elemento mais importante do acervo por reunir os chamados bens culturais (objetos, artefatos e construções que são obtidas a partir da transformação do meio ambiente e do saber fazer). Concentra-se nesse último grupo o desenvolvimento do texto contido no livro de Lemos: "O que é Patrimônio Histórico?" (Ed. Brasiliense: São Paulo, 1981 - Coleção Primeiros passo). Para o autor é necessário o entendimento de três importantes fatores que devem ser levados em conta no processo que envolve a escolha de um patrimônio histórico arquitetônico: (a) porque preservar, (b) o que preservar e (c) como preservar?

O objetivo maior na questão do porquê preservar situa-se no processo de garantir a compreensão e o desenvolvimento de uma identidade social ligada àssuas formas diferenciadas de manifestações, organizações e expressões de seus modos de vida - cultura, tendo na memória social (individual e coletiva) a base para essa compreensão e valorização. $\mathrm{O}$ patrimônio cultural (histórico-artístico-arquitetônico / natural / intangível- saberes, técnicas, lembranças) consiste numa simbologia social de pertencimento social, (como forma de coesão, em diferentes escalas). $\mathrm{Na}$ questão do que preservar, fatores de ordem burocrática e ideológica se encontram atreladas a interesses do poder público e a grupos específicos. Dessa forma, mesmo que a preservação do patrimônio cultural seja uma prática social, a sua construção e defesa esbarram em obstáculos políticos-ideológicos. Por esse motivo, o patrimônio não deve deixar de ser compreendido enquanto uma ferramenta do poder público, principalmente no campo nacional, em queo desenvolvimento de uma identidade 
nacional atrelada ao patrimônio representa uma força política essencial na defesa do território. Sua difusão está atrelada e dependente das nuances e interpretações que o patrimônio apresenta e as interferências postas em curso por instituições que regulam o processo de escolha, preservação e uso, sempre baseados em leis, normas e decretos que direcionam os artefatos escolhidos para a preservação.

O montante de legislações seguidas pelos órgãos públicos é enorme, sejam elas atribuídas pela Unesco ou pelo próprio Estado nacional nas suas diferentes escalas. Suas escolhas e manutenções ficam sempre a cargo das ideologias e prioridades escolhidas pelos órgãos públicos, visto os casos em que a sociedade toma pra si as escolhas e responsabilidades, baseadas no sentimento identitário que as liga ao patrimônio escolhido.

Com relação ao processo de como preservar se faz em termos práticos, visto que o reconhecimento e legitimação de um artefato é a parte mais simples do processo, já que esse pode ser feito por indivíduos, grupos específicos, comunidade, corpo acadêmico e a sociedade como um todo. A legalização do artefato, transformando-o em um patrimônio, corresponde a várias fases de estudos, embasamento legal e cientifico, mas sempre atrelados às vontades do poder público. Nesse sentido, a inserção do artefato a um livro de tombamento, constitui a primeira fase legal desse processo. Mas mesmo nesse estágio, o artefato ainda não pode ser considerado um patrimônio, visto que o termo patrimônio cultural pertence a toda a sociedade, e nessa fase, o bem tombado pertence somente ao poder público. Essa fase corresponde tanto ao patrimônio tangível como intangível.

Com relação ao patrimônio tangível relacionado quase sempre a edificações, outras fases legais são atribuídas: restaura- ção e uso didático e turístico do agora então, patrimônio. Contudo, essas fases são muito demoradas e burocráticas, visto que o processo de restauro exige profissionais da área e verba pública, fatores de maior obstáculo ao processo. Sendo comuns, bens tombados que permanecem por décadas interditados e degradando-se no tempo, a espera das resoluções burocráticas.

\section{SURGIMENTO DA CATEGORIA PATRIMÔNIO CULTURAL IMATERIAL (INTANGÍVEL)}

Como visto na classificação da Unesco de 1983, a denominação de patrimônio imaterial nem era cogitada, vindo a ser discutida somente no ano de 2003, na chamada “Convenção para a Salvaguarda do Patrimônio Imaterial", relacionada à cultura popular dos países, ligada àsmanifestações artísticas, principalmente de comunidades tidas como tradicionais, objetivando o respeito e a preservação dos valores culturais bem como sua reprodução no cotidiano social ao qual pertence.

Entende-se por Patrimônio Cultural Imaterial as práticas, representações, expressões, conhecimentos e técnicas - junto com os instrumentos, objetos, artefatos e lugares culturais que lhes são associados - que as comunidades, os grupos e, em alguns casos, os indivíduos reconhecem como parte integrante de seu patrimônio cultural. Este Patrimônio Cultural Imaterial, que se transmite de geração em geração, é constantemente recriado pelas comunidades e grupos em função de seu ambiente, de sua interação com a natureza e de sua história, gerando um sentimento de identidade e continuidade e contribuindo assim para promover o respeito à diversidade cultural e à criatividade humana. Para os fins da presente Convenção, será levado em conta apenas o Patrimônio Cultural Imaterial que seja compativel com os instrumentos internacionais 
de direitos humanos existentes e com os imperativos de respeito mútuo entre comunidades, grupos e indivíduos, e do desenvolvimento sustentável (grifo nosso) (ORGANIZAÇÃO DAS NAÇÕES UNIDADES PARA A EDUCAÇÃO, A CIÊNCIA E A CULTURA / UNESCO, 2006).

O trecho da citação em destaqueexemplifica os métodos utilizados pela Unesco no processo de escolha dos patrimônios culturais intangíveis, que tende a obedecer às normas internacionais de classificação, mesmo a Unesco afirmando a importância das culturas locais. Não se sabe ao certo se é em virtude de tais constatações ou mero acaso, mas novos métodos de classificação do patrimônio cultural vêm, aos pouco sendo recriados por grupos sociais em diferentes espaços globais.

Desta forma, o cenário patrimonial brasileiro sempre se encontrou subordinado às regras da Unesco, contudo, a diversidade cultural do Brasil é tão variada que as suas formas de reconhecimento e valorização não podiam ser diferentes. Assim, inúmeras propostas aparecem em diferentes pontos do território, formuladas quase sempre pela sociedade e amparadas pelo poder público, que visam o reconhecimento, preservação e valor econômico do patrimônio cultural tangível e intangível.

Castro (2008) traz, em seu livro intitulado "Patrimônio Imaterial no Brasil: Legislação e Políticas Estaduais", um apanhado da trajetória legal que envolve a questão do patrimônio cultural imaterial (Intangível) brasileiro, através das leis criados por alguns estados como forma de atender a demanda de indicações patrimoniais, demonstrando o interesse e a preocupação social e pública que existe emrelação a essa categoria do patrimônio cultural. Contudo, o estado do Paraná é exemplificado no livro como um dos estados que não possui essas leis, obedecendo aos critérios nacionais e regidos por outros órgãos de interesse, o que acaba gerando um grande atraso no andamento de qualquer ação referente à escolha e reconhecimento dos patrimônios imateriais.

Mesmo nos estados que ainda não dispõem de legislação para a preservação do patrimônio cultural imaterial, várias ações são desenvolvidas com essa finalidade, ou conduzidas pelo Iphan, ou pelos órgãos estaduais de cultura ou por outras instituições. Um bom exemplo é o projeto Paraná da gente, desenvolvido pela Secretaria Estadual de Cultura do Paraná, que constou de um amplo inventário nos municípios do estado, com questionários aplicados por agentes de cultura locais, e que resultou em uma série de publicações distribuídas às prefeituras e às bibliotecas públicas (CASTRO, 2008, p.97).

Outros estados, porém, despontam na frente e criam suas próprias leis como forma de valorizar suas culturas regionais, mas sempre subordinados às determinações gerais da UNESCO.

No estado do Rio Grande do Norte foi criado pela Fundação José Augusto o "Inventário do Patrimônio Potiguar", contendo dados culturais regionais, e uma classificação de patrimônio intangível que visa o local.

Patrimônio Imaterial engloba os saberes e ofícios, as formas de expressão, os lugares de sociabilidade e as festas e celebrações populares. É um retrato vívido da alma do povo, das suas formas de sentir, de saber, de fazer. No Rio Grande do Norte, elas foram catalogadas por Luís da Câmara Cascudo, que dedicou todo o seu trabalho intelectual a preservar e enaltecer o patrimônio imaterial do povo brasileiro (RIO GRANDE DO NORTE, 2006, p.02).

Outra proposta com enfoque similar diz respeito ao estado de Pernambuco, o qual possui um programa de apoio e Registro do PatrimônioVivo do Estado de Pernambuco (RPV-PE), apoiado pelo 
órgão de Política Cultural do Estado Fundarpe $^{6}$ e amparados pela Portaria $\mathrm{n}^{0} 05$ de 24/08/2009 (PERNAMBUCO, 2009), baseado no programa "Tesouros Humanos Vivos" criado ano de 1993 pela Unesco. A proposta de Pernambuco busca através de um concurso público anual, registrar como patrimônios não só as manifestações artísticas, mas também os artistas ainda vivos, culturalmente ativos a mais de 20 anos no estado. O programa, através dessa forma de reconhecimento, financia os ganhadores, com bolsas de incentivo financeiro do Governo, premiando pessoas físicas com um valor de $\mathrm{R} \$ 750,00$ e pessoas jurídicas, de natureza cultural disposta em Estatuto, com o valor de $\mathrm{R} \$ 1.500,00^{7}$. Para participar do concurso, os candidatos tem que apresentar inúmeros requisitos para serem selecionados, mas o principal refere-se à produção artística que desempenha no estado de Pernambuco e o comprometimento de sua continuidade.

Apesar de ter status econômico, o programa de preservação ao Patrimônio Vivo de Pernambuco merece destaque pelo incentivo que dá não só àcultura local, mas principalmente aos agentes sociais produtores dessa cultura. Sua importância encontra-se no processo de pertencimento social, pelo qual passa a Identidade social, assim como na tomada de consciência social e entendimento crítico do patrimônio, comum na sociedade cultural europeia do século XIX, possuindo assim, uma significativa representatividade junto à sociedade, pois os "patrimônios" escolhidos são indicados pela própria sociedade.

\footnotetext{
${ }^{6}$ No ano de 2009 foi destinada mais de $\mathrm{R} \$ 123$ milhões de reais a fundação, para serem investidos na área cultural, segundo a prestação de conta do Estado.

${ }^{7}$ PERNAMBUCO, 2009. Disponível em: http:/ / www.fundarpe. pe.gov.br/fomento_editais.php
}

\section{INTERVENÇÕES POLÍTICAS, CIENTÍFICAS E SOCIAIS COM RELAÇÃO À PRESERVAÇÃO DO PATRIMÔNIO FERROVIÁRIO BRASILEIRO}

Antes de falar da ferrovia como patrimônio histórico brasileiro é necessário esboçar um resumo de sua implantação no território brasileiro, e de como a atmosfera de progresso que tomou conta da população do século XIX levou a ferrovia a ser reconhecida como patrimônio cultural.

A implantação da estrutura ferroviária no território brasileiro deu-se nos anos de 1852, trazendo o progresso para uma sociedade que até então, era mediada pelo tempo da carroça. De fato, toda a vida econômica, social, política e cultural passou a depender quase que exclusivamente da ferrovia. Os transportes de pessoas e mercadoria eram feitos pelos trilhos que ligavam o interior do país aos grandes centros urbanos. Desses, chegavam as mais diferentes variedades de produtos, serviços, informações e pessoas.

Em seus estudos realizados na região dos Campos Gerais - PR, Monastirsky (1997) afirma que, nas cidades do Paraná, houve a implantação de um modelo cultural desenvolvimentista, incentivado pela propaganda da então implantada República, que via nas inovações tecnológicas - estrutura ferroviária, entre outras - os propulsores das mudanças sociais e culturais do país, característica vivenciada por todo o território nacional. A sociedade do fim do século XIX enfim é influenciada pela onda cultural dos países centrais. Esse efeito jamais tinha sido sentido com tanta força na região. Viveu-se uma nova ordem cultural, a Bélle Époque, "feitas de representações, de ideais, de valores e de sentimentos que se tornaram comuns a todos os indivíduos" (p.92). 
O fenômeno em que se transformou a estrutura ferroviária brasileira corresponde a uma. No livro "A era do Capital" (2004), Eric Hobsbawm mostra as transformações geradas pela implantação de inúmeras técnicas no cenário europeu, destacando como uma das mais importantes à estrutura ferroviária, propulsora do desenvolvimento territorial. Para o autor, o século XIX sinaliza a ruptura entre dois momentos: o mundo conhecido e o mundo unificado. Até esse período com a implantação de novas técnicas de transportes e deslocamento, os lugares eram conhecidos por poucos, através de processos de colonização e exploração, através da navegação e tração-animal. A decadência do reconhecimento e mapeamento dos lugares consistia numa ignorância diplomática entre os países e reinados. Cada país criava suas estratégias de negociação e por seguinte, suas poucas rotas de venda.

Contudo, a Europa a partir de 1830, passa a ter uma alta demanda por matérias-primas como algodão para as indústrias têxteis, e, por conseguinte, máquinas de processamento construídas com ferro vindo de outros países, num processo de aumento contínuo do capital industrial. Nessa era de revoluções técnicas a estrutura ferroviária surge como principal mediadora entre a produção e o capital final, moldando um novo cenário comunicativo entre os lugares.

(...) o espaço geográfico da economia capitalista poderia repentinamente multiplicar-se, na medida em que a intensidade das transações comerciais aumentasse. $\mathrm{O}$ mundo inteiro tornou-se parte desta economia. Esta criação de um único mundo expandido é talvez a mais importante manifestação do nosso período (HOBSBAWM, 2004, p.49).

Os trilhos da ferrovia passaram a levar ao mundo muito mais de que novos produtos, as pessoas passaram a conhecer um mundo que até então não existia. Com as informações chegando diariamente nos locais que, até então eram remotos, o cotidiano das cidades ferroviárias ganhou impulso, sustentado pelas novidades que chegavam com o trem. Essa idealização da Bélle Époque justifica o processo de valorização e mitificação da ferrovia pelas pessoas que presenciaram essa época. Transformadora dos modos de vida da sociedade, a estrutura ferroviária foi amaterialização do que se entendia por poder. A Estrada de Ferro São Paulo - Rio Grande, construída pela empresa "Brazil Railway Company", a qual corta o Paraná, de sul a norte, constitui-se como uma gigantesca empresa, detentora do meio de transporte, mais usado até então (MONASTIRSKY, 1997, p.48).

A implantação da ferrovia no território brasileiro leva a uma nova ordem espacial, mesmo nos lugares que se configuravam como ponto de passagem dos trens, a ferrovia realizou a integração das cidades menores a grandes centros urbanos, desenvolvendo arranjos comerciais, nunca vistos no espaço ate então, contribuindo com o processo de transição da sociedade rural para a urbana.

Outro fator que explica a sua força foram as contratações exorbitantes de funcionários realizadas pela empresa. $\mathrm{Na}$ construção da estrada de Santos a Jundiaí, pela Companhia Paulista, no início do século XIX, foram contratados 5.257 trabalhadores, dos mais variados cargos, para sua execução (ZAMBELLO, 2005, p.50), chegando à somatória nacional de 51 mil ferroviários, em 1957, no ano de criação da RFFSA (MONASTIRSKY, 2006, p.89) e mais de 43 mil trabalhadores no ano de 1929, nas estradas paulistas (MOREIRA, 2008, p.80).

A estrada de ferro, implantada no Brasil no final do século XIX, manteve seu auge até a década de 1950, quando o transporte ferroviário começou a declinar, vindo a 
ser substituído pelo transporte rodoviário. Essa crise explica-se por diversos motivos, tais como a incompatibilidade de equipamentos ferroviários, a exemplo das bitolas ${ }^{8}$ vindas da Inglaterra, com padrões diferentes das encontradas nas construções de trechos de linhas, que se encontravam espalhadas pelo território nacional, sendo impossíveis suas ligações.

Um dos principais fatores desencadeador da crise encontra-se na escolha dos investimentos de capital, que passaram a ser empregados em projetos rodoviários. As novas malhas rodoviárias passaram a fazer parte das chamadas políticas desenvolvimentistas, que perduraram pelas décadas de 1920 a 1950, sob o comando de diferentes governantes. Juntando-se a isso, o incentivo ao capital estrangeiro e a abertura políticatransferiramàs montadoras automobilísticas e àsmultinacionais as oportunidades, que até então pertenciam às empresas ferroviárias. Desse momento em diante, a ferrovia começa a passar por um processo de sucateamento e privatizações.

A estrada de ferro que cortava o território brasileiro passou a não atender mais a busca por novos mercados consumidores, assim, as ramificações férreas pararam no tempo e passaram a ser substituídas por novos meios de comunicação mais rápidos - as rodovias.

Milton Santos (2006, p.171) caracteriza essa transformação como parte de um processo contínuo de transformação do meio geográfico como Tecnosfera e Psicosfera. Esse processo tem início, se é que podemos pontuá-lo, com a transformação desse meio geográfico pela sociedade, que vê nas "formas" historicamente herdadas, a necessidade de novos usos e novas aplicações de técnicas que possam atender a demanda inicial. A implantação de novas técnicas gera a Tecnosfera, que tem suas

${ }^{8}$ Modelo padronizado de medida de trilhos. origens na ciência e na tecnologia, destinada unicamente a alavancar a produção, comercialização e o capital industrial, tendo como principal foco a substituição da técnica anterior. A Tecnosfera está diretamente vinculada àPsicosfera, ou seja, enquanto a primeira está ligada àracionalidade da técnica, a segunda liga-se aos valores ideológicos e a um imaginário social de progresso. A manifestação desse fenômeno depende dos agentes sociais que moldam o espaço geográfico.

Esse fenômeno pode ser observado com a implantação da Ferrovia em diferentes partes do mundo e a idealização da então chamada Bélle Époque vem justificar a valorização e a mitificação que a Ferrovia adquiriu ao longo do tempo.

Diante da importância histórica e cultural dessa estrutura em todo o Brasil, surgem no cenário social e acadêmico, ações que buscam o reconhecimento da ferrovia como bem cultural e participação do poder público nos processos de proteção e preservação da estrutura ferroviária, manifestadas através de pesquisas científicas, sindicatos de trabalhadores ferroviários e grupos de admiradores da história ferroviária, que se espalham pelo Brasil.

As manifestações sociais emrelação ao Patrimônio Cultural caminham a passos lentos, mas alguns exemplos demostram o início de uma tomada de consciência.

Consciência essa que se manifestou na Europa do século XIX, onde a ferrovia já estava classificada enquanto arquitetura industrial. Todo o desenvolvimento tecnológico empregado a ela e desenvolvido por ela tornou-se um bem patrimonial, reconhecido pelo Estado e protegido pela legislação.

No Brasil, o reconhecimento do patrimônio ferroviário se dá de forma isolada no espaço, mesmo sendo administrada pelo órgão Federal IPHAN. São encontradas leis estaduais como no caso do Estado 
de Minas Gerais, onde o Projeto de lei $n^{\circ}$ 3.056/2009, (MINAS GERAIS, 2009), "estabelece normas para a preservação e para a promoção do patrimônio cultural associado ao transporte ferroviário, como forma de desenvolver o turismo". Outro interesse diz respeito à preservação das Estações, presentes em quase todas as cidades por onde a malha ferroviária passa ou passou. Nesse sentido, o debate é motivado pela proteção arquitetônica, como forma de preservação histórica da memória e desenvolvimento local. As propostas geralmente dizem respeito à transformação dessas estruturas em espaços de memória, ou seja, museus ${ }^{9}$. Para o IPHAN, a preservação das estações é um caminho para o desenvolvimento das identidades locais.

Esse órgão também é responsável por classificar o patrimônio ferroviário em tangível e intangível. O primeiro é representado pela estrutura física denominada de Patrimônio Industrial, o qual "englobam edifícios e maquinaria, oficinas, fábricas, minas e locais de processamento e de refinação, entrepostos e armazéns, centros de produção, transmissão e utilização de energia, meios de transporte e todas as suas estruturas e infraestruturas, habitações, locais de culto ou de educação" ${ }^{10}$. Já o termo Imaterial, ligado às manifestações populares, é relacionado às antigas estações ferroviárias, representantes das memórias locais.

Nesse contexto, outras propostas buscam novos entendimentos com relação ao patrimônio intangível ferroviário, não somente relacionado às estações ferroviárias, mas, sobretudo ao papel desempenhado

\footnotetext{
${ }^{9}$ Com relação àtemática "Museus" foi realizado na Unicamp o "Seminário Latino-Americano Museologia e ferrovia", nos dias 26 e 27 de outubro de 2009, o qual reuniu especialistas de vários países. Nesse foram discutidos projetos de transformação das estações ferroviárias em museus, tendo o apoio do CNPQ, através do incentivo a pesquisa. Disponível em: http://desafios2. ipea.gov.br/003/00301009.jsp?ttCD_CHAVE=12645

${ }^{10}$ Disponível em: http://www.unicamp.br/unicamp/unicamp_hoje/ju/outubro2006/ju341pag10a.html
}

pelos milhares de trabalhadores que fizeram parte da história da ferrovia brasileira, mas que não são reconhecidos pelo IPHAN enquanto membro do acervo patrimonial ferroviário.

\section{O TRABALHADOR FERROVIÁRIO E SUA REPRESENTATIVIDADE JUNTO AO PATRIMÔNIO CULTURAL INTANGÍVEL}

O papel do trabalhador ferroviário enquanto objeto de estudo cientifico, aparece em algumas obras: Inácio (2003); Petuba (2005); Monastirsky (1997/2006); Moreira (2008); Zambello (2005). Nesses estudos o trabalhador ferroviário tem destaque através do relato de suas histórias de vida, ligadas ao trabalho na ferrovia.

Tendo em vista a escolha do trabalhador como principal elemento de análise, a pesquisa que se encontra em andamento, tem como objetivo central o reconhecimento do trabalhador ferroviário das décadas de 1940 a1960, enquanto um "Patrimônio Vivo da Sociedade" através da investigação da sua participação na construção simbólica da ferrovia no Paraná e, consequentemente no Brasil.

A escolha do recorte temporal que compreende as décadas de 1940 a 1960, pautou-se no reconhecimento deque esse agente social, ao vivenciar a chamada Bélle époque da Ferrovia, colaborou com o processo de mitificação da mesma. Seja pelo papel desempenhado na formação do espaço paranaense ou pela legitimação política que exerceram ao colaborarem com a criação de associações e sindicatos, esses trabalhadores ferroviários detém vivo na memória as histórias desse passado.

O trabalhador ferroviário destacou-se no meio social, principalmente durante a primeira metade do século $\mathrm{XX}$, com as 
suas vantagens trabalhistas, mas, essencialmente, por representar e participar de uma organização mitificada desde a sua implantação. Com os ferroviários há toda uma gama de bens e manifestações culturais significativos como referências de grupos sociais "formadores da sociedade brasileira” (MONASTIRSKY, 2006, p.90).

Os trabalhadores ferroviários sempre tiveram destaque nos discursos cotidianos da população, como pode ser constatado nas primeiras abordagens de campo, do referido objeto de pesquisa, como sendo esse, um agente fundamental na construção e manutenção da estrutura ferroviária do Paraná, assim, destacando-se também como uma classe operária economicamente bem sucedida.

A estabilidade de emprego, a política de ascensão de níveis, a moradia de boa qualidade, organizada em vilas de operários, a regularidade do pagamento mensal e um poder de compra acima da média da classe assalariada determinou a boa relação do ferroviário com a empresa e com a comunidade (MONASTIRSKY, 1997, p. 90).

Entretanto, a generalização da ideia de uma classe de operários ferroviários sempre bem remunerada é rebatida por Inácio (2003), ao estudar, por exemplo, os turneiros, classe tida como a mais desvalorizada da empresa ferroviária, focando "as transformações nas relações de trabalho ocorridas entre os anos de 1950 e 1970, na antiga Estrada de Ferro Goiás".

Foi possível perceber que a experiência de turmeiro sinaliza traumas que os trabalhadores sofreram: a entrada para a empresa e o confronto entre novas maneiras de trabalhar e as diferenças com horário, disciplina, hierarquia. Isso fez com que sentissem alterações em suas vidas e um rompimento com o passado, experimentado em atividades que desempenhavam em fazendas da região (INÁCIO 2003, p. 11).
Na observação de Zambello (2005), os ferroviários fazem parte de um grupo queé vinculado a um trabalho e a um espaço específico, a ferrovia. Nesse caso, o indivíduo não pode ser compreendido por completo sem que haja referências desse à instituição que o formou, enquanto trabalhador.

A vida do indivíduo não pode ser compreendida adequadamente sem referência às instituições dentro da qual sua biografia se desenrola, pois esta biografia registra a aquisição, abandono, modificação e, de forma muito íntima, a passagem de papéis que o indivíduo ocupou, ou ocupa na vida (ZAMBELLO, 2005, p. 313).

Dessa maneira, se a ferrovia constituiu-se num elemento transformador das relações sociais e do espaço das cidades do Paraná das décadas de 1940 a 1960, o trabalhador ferroviário desse período, com idade a cima de 60 anos, possui as lembranças dos relatos históricos dessas transformações.

No bojo da Geografia Cultural, a memória social passa ser "utilizada como um instrumento de construção cultural assim como, um método de análise" apresentando-se como abordagem metodológica de estudo sobre o passado. A memória coletiva passou a constituir-se enquanto busca de pertencimento e afirmação identitária de indivíduos que compõem um grupo social específico, pois essa contém o registro da vivência dos indivíduos. Para Bosi (1994, p. 413) "a memória individual é um ponto de vista sobre a memória coletiva". É o indivíduo que detém o poder de memorizar e dar significado aos objetos e histórias ocorridas num passado em comum. O processo de "valorização da memória dos sujeitos apresenta-se como oportunidade de trazer à tona outras histórias e outros olhares sobre o passado" (PETUBA, 2005, p. 12).

No estudo para compreender o papel do trabalhador ferroviário entende-se 
que esse se apresenta como um agente social que colaborou com a configuração histórica / econômica e cultural do espaço urbano, com sua força de trabalho, com seu poder de capital, com sua posição social e trabalhista (sindicatos e associações), e como detentor do conhecimento no ato de "saber fazer".

A memória individual contém as lembranças das coisas vividas por cada indivíduo com a ferrovia, mas contém também uma carga simbólica proveniente da propaganda pró-ferrovia e do efeito das atividades ferroviárias em todas as escalas espaciais e temporais (...). As lembranças das pessoas que vivenciaram a ferrovia e daqueles que nela trabalharam, além de legitimar a ferrovia como um patrimônio cultural, auxiliam no fortalecimento e perpetuação da memória coletiva e possibilita o reconhecimento da cultura local e da sua participação num contexto regional e nacional. (MONASTIRSKY, 2006, p. 12).

Para compreender a representatividade desses agentes sociais buscou-se aqui substituir a palavra agente pela expressão "categoria social", consistindo num grupo social específico que mantendo entre si, características comuns (sexo, idade, gênero, nacionalidade, atividade). A escolha dessa expressão é defendida nos estudos sobre os idosos, na obra "Memória e sociedade lembranças de velhos" de Ecléa Bosi (1994).

Além de ser um destino do indivíduo, a velhice é uma categoria social (...) cada sociedade vive de forma diferente o declínio biológico do homem. A sociedade industrial é maléfica para a velhice. Nas sociedades mais estáveis um octogenário pode começar a construção de uma casa, a plantação de uma horta, pode preparar os canteiros e semear um jardim. Seu filho continuará a obra (BOSI, 1994, p. 77).

Nessa obra, a autora trabalha o papel que os velhos têm diante da sociedade capitalista contemporânea. Essa representatividade é mostrada em sua obra, através das memórias colhidas de vários indivíduos. Com relação às categorias sociais, essas aparecem nos trabalhos científicos como uma construção conceitual, determinada pelo pesquisador no processo de investigação social, ganhando validade quando trabalhadas na base de um grupo social especifico. Escolha que pode também aparecer nos discursos dos grupos estudados, usada para autodenominar-se ${ }^{11}$.

$\mathrm{Na}$ busca pela representatividade social do trabalhador ferroviário, o entendimento e o reconhecimento desses agentes sociais em "Patrimônio Vivo da Socieda$\mathrm{de}^{\prime \prime}$, faz parte de uma iniciativa científica e social de inserção desses trabalhadores no acervo que compõe o patrimônio ferroviário. Dessa forma, sendo o patrimônio cultural uma construção social, o sentimento de pertencimento àsociedade pode ser despertado também pelo reconhecimento de seu passado através das histórias daqueles que participaram da construção histórica e cultural do país.

\section{CONSIDERAÇÕES FINAIS}

Vários exemplos de trabalhos de preservação dos diferentes patrimônios vêm surgindo no Brasil num processo conjunto entre Estado e sociedade. Contudo, as abordagens patrimoniais são complexas e

\footnotetext{
${ }^{11}$ As categorias utilizadas pelo investigador no seu trabalho são construídas com base num conjunto de pressupostos, a partir de determinado ponto de vista sobre a realidade, e destinadas a certos fins - é o caso, por exemplo, das categorias que encontramos estabelecidas nas estatísticas oficiais. Para utilizar, bem como para construir, as próprias categorias, o investigador tem, portanto, de efetuar um trabalho crítico de "desconstrução" de uma realidade que se apresenta como tendo validade em si própria, isto é, tem de conhecer aqueles critérios e aquele ponto de vista para poder perceber qual o significado e qual a validade das categorias, sabendo que a utilização de indicadores diferentes dará origem a resultados diferentes. A escolha de estudar os trabalhadores ferroviários enquanto categoria de análise, também aparece nos estudos de Moreira (2008), realizado com trabalhadores da Estrada de Ferro Sorocabana - SP.
} 
merecem atenção e um entendimento crítico. Primeiro, as formas de classificações dos Patrimônios devem levar em conta as escolhas sociais, já que as mesmas participam dialeticamente do processo cultural. Segundo, a função do Patrimônio, ou seja, sua utilidade não precisa ficar restrita ao uso econômico, comum ao turismo cultural. Terceiro, a categoria de valor deve estender suas fronteiras para além do patrimônio tangível edificado, reconhecendo, mesmo que tardiamente, os agentes sociais que constroem cotidianamente a cultura e o espaço social.

Outras questões de ordem teórico-críticas podem ser levantadas a respeito desses processos e devem ser levadas em conta no processo de reconhecimento, restauração e conservação do patrimônio tangível ou intangível: A quem pertence à autenticidade da obra restaurada, ao artista original ou ao restaurador? Se o patrimônio representa a identidade de uma sociedade, porque o poder público transforma o patrimônio numa fonte de renda turística, cobrando dessa mesma população que se liga simbolicamente a esse patrimônio? Porque o sentido didático do patrimônio é quase sempre deixado de lado? Porque o processo de reconhecimento e preservação não é contemplado na sua totalidade, visto a degradação e o abandono de várias estações ferroviárias e locomotivas espalhadas pelo país, sem contar as inúmeras construções históricas, muitas vezes em processo de reconhecimento que levam anos, deteriorando-se a espera da vontade pública?

Tais questões devem-se talvez, ao mesmo processo denominado de "onda cultural", vinda dos países centrais, carregadas de ideologias, que por inúmeros motivos, não servemde modelo aos países periféricos. Visto que as mesmas leis aplicadas nesses países centrais (desenvolvidos economicamente e culturalmente) são também aplicadas nos países periféricos. Como consequência tem-se uma profunda distorção do conhecimento acerca do patrimônio e das leis que o regem. A sociedade, na sua maioria, carece dos serviços básicos para sobrevivência, refletindo assim, numa banalização e desinteresse com relação à questão do patrimônio cultural nas diferentes escalas.

Diante das abordagens sobre o patrimônio cultural, o estudo de categorias sociais enfocando as memórias dos trabalhadores ferroviários, possui uma significância que vai além da simples coleta de histórias sobre a ferrovia brasileira. Suas memórias são o resultado de anos de vida dedicados ao trabalho em uma empresa que se tornou símbolo de prosperidade e progresso em todos os países em que foi implantada. Visualizá-las pelo prisma do patrimônio cultural intangível denota uma valorização do papel por eles desempenhado e uma complementação do acervo que compõem o patrimônio ferroviário.

\section{REFERÊNCIAS}

ABREU, R.A emergência do patrimônio genético e a nova configuração do campo do patrimônio. In: ABREU, R.; CHAGAS, M. (org.). Memória e patrimônio: ensaios contemporâneos. Rio de Janeiro: DP\&A, 2003.

BOSI, E. Memória e sociedade: lembranças de velhos. 3ed. São Paulo: Cia das Letras, 1994.

CASTRO, M. L. V.; FONSECA, M. C. L.Patrimônio Imaterial no Brasil: Legislação e Políticas Estaduais. Brasília: Unesco, Educarte, 2008.199 p.

CHAUI, M. O que é Ideologia. Brasiliense: São Paulo,1980.

CHOAY, F. A alegoria do Patrimônio. São Paulo: Unesp, 2001.

GONÇALVES, J. R. S. O patrimônio como categoria de pensamento. In: ABREU, Regina; CHAGAS, Mário. (orgs.). Memória e patrimônio: ensaios contemporâneos. Rio de Janeiro: DP\&A, 2003. 
HOBSBAWM, E. J. A era do Capital: 1848-1875. 3 ed. São Paulo: Paz e Terra, 2004.

INÁCIO, P. C. Trabalho, ferrovia e memória: a experiência de Turmeiro (a) no Trabalho Ferroviário, 2003, 128f. Dissertação. Universidade Federal de Uberlândia, Uberlândia, 2003.

\section{LEMOS. C. A. C. O que é Patrimônio Histórico?} Brasiliense: São Paulo, 1981.

MINAS GERAIS. Projeto de Lei $\mathbf{n}^{\circ} 3.056$ de 21 de fevereiro de 2009. Altera a Lei ${ }^{\circ} 11.726$, de 30 de dezembro de 1994, que dispõe sobre a política cultural do Estado de Minas Gerais, e a Lei n ${ }^{\circ} 12.398$, de 12 de dezembro de 1996, que dispõe sobre o Plano Mineiro de Turismo e dá outras providências. Disponível em: http://ws.mp.mg.gov.br/biblio/ informa/270211483.htm. Acessado em: ago. 2010.

MONASTIRSKY, L. B. Cidade e Ferrovia: a mitificação do pátio central da RFFSA em Ponta Grossa. 1997, 190 f. Dissertação. Universidade Federal de Santa Catarina, Florianópolis, 1997.

Ferrovia: patrimônio cultural estudo sobre a ferrovia brasileira a partir da região dos Campos Gerais (PG), 2006, $190 \mathrm{f}$. Tese Doutorado. Universidade Federal de Santa Catarina. Florianópolis, 2006.

MOREIRA, M. F. S. Ferroviários, Trabalho e Poder. São Paulo: Unesp, 2008.

ORGANIZAÇÃO DAS NAÇÕES UNIDADES PARA A EDUCAÇÃO, A CIÊNCIA E A CULTURA / UNESCO. Convenção para a salvaguarda do patrimônio cultural imaterial.MISC/2003/CLT/ CH/14. Paris, 17 de outubro de 2003. Documento originalmente publicado pela UNESCO sobre o título Convention for theSafeguardingoftheIntangible Cultural Heritage, Paris, 17 October 2003. Tradução feita pelo Ministério das Relações Exteriores, Brasília, 2006. Disponível em: http:/ / unesdoc. unesco.org/images/0013/001325/132540por.pdf. Acessado em: ago. 2010.

PERNAMBUCO. Lei $\mathbf{n}^{\circ} \mathbf{1 2 . 1 9 6}$, de 02 de maio de 2002, de Registro do Patrimônio Vivo do Estado de Pernambuco - RPV-PE. Visa Regulamento do Concurso público do registro do Patrimônio Vivo do Estado de Pernambuco - RPV - PE/edição 2009. Disponível em: http:/ / www.fundarpe.pe.gov.br/ fomento_editais.php. Acessado em: ago. 2010).

. Portaria FUNDARPE ${ }^{0}$ 05, de 24/08/2009. Art. 25, inc. I e XVI do Decreto Estadual n. 21.548, de 09 de julho de 1999. Fundação do Patrimônio Histórico e Artístico de Pernambuco - FUNDARPE. Disponível em: http://www.fundarpe.pe.gov.br/
portaria-fundarpe-n-05-de-24082009Acessado em: out. 2010).

PETUBA, R. Ser trabalhador ferroviário na cidade de Ponta Grossa: escutando outras falas, desvendando outras memórias (1940-2000). Revista de História e estudos culturais. V. 2, n. 2. Abril/Maio/ Junho de 2005.

RIO GRANDE DO NORTE. Fundação José Augusto. Instituto de Formação e Gestão em Turismo do Rio Grande do Norte. Patrimônio Imaterial. Isaura Amélia de Souza Rosado Maia; Tricia Rosado Maia (org.); Giovanni Sergio (il.). - Natal (RN): Fundação Jose Augusto, 2006. (Coleção Patrimônio Cultural Potiguar, 6). $12 \mathrm{p}$.

SANTOS, M. A Natureza do Espaço: Técnica e Tempo, Razão e Emoção. $4^{a}$ ed. São Paulo: USP, 2006.

ZAMBELLO, M. H. Ferrovia e memória: estudo sobre o trabalho e a categoria dos antigos ferroviários da Vila Industrial de Campinas, 2005, 367 f.Dissertação (Mestrado em Sociologia, Faculdade de Filosofia, Letras e Ciências Humanas) - Universidade de São Paulo, São Paulo, 2005.

Recebido em: 19/06/11 Aceito em: 26/08/11 